\title{
NOS RASTROS DA ÁREA DA RELIGIÃO NA UFMG: ALGUMAS NOTAS E BREVES REMINISCÊNCIAS ${ }^{1}$
}

Léa Freitas Perez

Resumo: $\mathrm{O}$ ensino e a pesquisa na área da religião são campos consolidados no Departamento de Sociologia e Antropologia da Faculdade de Filosofia e Ciências Humanas da Universidade Federal de Minas Gerais. O texto percorre, na espessura da história, certos momentos e acontecimentos que marcaram sua delimitação.

Palavras-chave: ensino e pesquisa, história, Antropologia da Religião, Sociologia da Religião, UFMG.

Abstract Teaching and research on religion is an established field of studies in the Sociology and Anthropology Department at the Federal University of Minas Gerais' Philosophy and Human Sciences College. The text pursues, in the thickness of history, certain moments and events which have framed it.

Keywords teaching and research, history, Anthropology of Religion, Sociology of Religion, UFMG.

Le sens doit attendre d'être dit ou écrit our s'habiter lui-même et devenir ce qu’à différer de soit il est: le sens (Jacques Derrida)

O ensino e a pesquisa na área da religião são campo consolidado no Departamento de Sociologia e Antropologia da Faculdade de Filosofia e Ciências Humanas da Universidade Federal de Minas Gerais.

\footnotetext{
${ }^{1}$ Este texto contou com a colaboração de algumas pessoas, para as quais sou profundamente grata e reconhecida. Pierre Sanchis concedeu-me a graça de escrever algumas notas e de tecer preciosas reminiscências. A professora Candice Vidal e Souza (PUC-MG) forneceu importantes informações sobre a história da Antropologia em MinasGerais. Pablo Juan Cândido da Silva e TitoTavares Coelho da Silva, alunos do Curso de Ciências Sociais da UFMG, trabalharam na pesquisa de dados.

2 Professora do Departamento de Sociologia e Antropologia e do Pragrama de Pós-Graduação em Antropologia Social Universidade Federal de Minas Gerais.
} 
É importante desde logo frisar que aqui não se faz uma história linear, mas tal como o título sugere, quer-se modestamente percorrer, na espessura da história, certos momentos e acontecimentos que marcaram a delimitação do campo da Religião, particularmente da Antropologia da Religião na UFMG. ${ }^{3}$

Um marco fundamental é o trabalho de ensino e pesquisa desenvolvido pelo antropólogo francês Pierre Sanchis, que foi professor da UFMG de 1978 a 1996, lotado no Departamento de Sociologia e Antropologia.

Concomitante à sua atuação na UFMG, desde 1976, Pierre é membro do Instituto de Estudosda Religião(ISER). Sua participação no ISER, muitas vezes, se não sempre, se deu em relação com sua atividade na UFMG, ou pelo menos, como menciona acarretava "uma participação belo-horizontina".

Foi presidente do ISER de 1982 a 1985, depois de ser membro de sua Comissão Executiva. É membro da comissão editorial da revista Religião e Sociedade, tendo sido também membro do conselho de redação dos Cadernos do ISER e membro da comissão editorial da coleção Religião e Modernidade. Ainda no ISER, foi coordenador do Grupo de Estudo do Catolicismo, posteriormente denominado Grupo de Estudo do Sincretismo.

No ISER, na maioria das vezes em ligação com seu trabalho na UFMG e com financiamento do $\mathrm{CNPq}$, realizou onze pesquisas que tinham como foco analítico e reflexivo principal o catolicismo brasileiro, quer em sua face institucional (por exemplo, as relações entre a igreja e as comunidades de base, e entreo Estadoe a Igreja), quer em sua face popular(com ênfaseespecial para a religiosidade negra em suas diferentes manifestações). A problemática do sincretismo, tanto como questãoteórica para a Antropologia quanto como realidade etnográfica para o pesquisador, ocupou boa parte das pesquisas. Uma destas pesquisas, de que resultou a organização de três coletâneas sobre o catolicismo (Sanchis, 1992a, 1992b, 1992c), foi realizada por uma equipe de vinte pesquisadores, de treze universidades brasileiras e duas americanas. Tambémcoordenou no CNPqpelo ladobrasileiro trêspesquisas intemacionais (França e Brasil) sobre identidades religiosas e identidades étnicas. Brasil,

${ }^{3} \mathrm{Na}$ escolha desses momentos atuam opções de destaque de proveniência disciplinar.

Debates do NER, Porto Alegre, ANO 8, N. 11, P. 119-133, JAN./Jun. 2007 
Portugale França,não escapam ao olhar arguto do pesquisador, do peregrino em romaria, do estrangeiro em viagem (três personas em uma) que nos faz percorrer através de suas instigantes análises do universo religioso através dos diferentes e dos diversos mundos culturais que compõem a vida em coletividade. Não se pode ainda deixar de mencionar as pesquisas que tratam de temas como o pecado, o Equador e o Atlântico, o mal à brasileira e a paixão na consciência popular brasileira.

Em 1991,fez pós-doutoradona Écoledes HautesÉtudes en Scienœs Sociales junto ao Grupo de Sociologia das Religiões do CNRS. Na UFMG, atuou no ensino (graduação e pós-graduação), na pesquisa e na administração, ininterruptamente desde sua chegada, como já referido, em 1978, até sua precoce aposentadoria em 1996. Recebeu o título de Professor Emérito desta Universidade em 1999, tendo sido o primeiro professor do Departamento de Sociologia e Antropologia a receber tal título na UFMG.

Antes de avançar cabe uma breve nota sobre a história da UFMG. A criação de uma universidade em Minas Gerais já fazia parte do projeto inconfidente, sendo finalmente realizada em 1927, com a fundação da Universidade de Minas Gerais (UMG), instituição privada, subsidiada pelo Estado,produto da junçãodas quatroescolas de nívelsuperior entãoexistentes em Belo Horizonte. ${ }^{4}$ A UFMG permaneceu na esfera estadual até 1949, quando foi federalizada. A denominação atual - Universidade Federal de Minas Gerais - foi adotada em 1965.

A Faculdade de Filosofia foi fundada em 21 de abril de 1939, tendo sido incorporada à Universidade de Minas Gerais em 1948. Sua atual denominação - Faculdade de Filosofia e Ciências Humanas (FAFICH) data da Reforma Universitária implantada pela Lei 5.540/68. Desde as instalaçõesno Edifício Acaica(no centrode Belo Horizonte),passando pelo célebre

${ }^{4}$ Cabe relembrar que no Brasil,a universidade foi implantada com a República como continuação de um processo iniciado no Império, com a abertura das primeiras escolas de nível superior no país. Em Minas Gerais, a primeira instituição de nível superior foi a Escola de Farmácia, de Ouro Preto, fundada em 1839. 
e saudoso prédio da Rua Carangola (no bairro Santo Antônio), às modernas instalações no Campusda Pampulha (para onde veio em 1990), a FAFICH viveu muitas e significativas mudanças.

O Departamento de Sociologia e Antropologia, um dos atuais seis departamentos da FAFICH, é resultado da fusão, em 1967, dos cursos de Bacharelado em Sociologia e Política e Administração Pública da Faculdade de CiênciasEconômicas e o de Licenciatura em CiênciasSociais da Faculdade de Filosofia e Ciências Humanas. Conta atualmente com 28 professores, dos quais apenas 8 são antropólogos. O SOA (como é familiarmente chamado) é responsável, junto com o Departamento de Ciência Política (o DCP) pelo Curso de Graduação em Ciências Sociais.

Até a reforma universitária, havia dois cursos de graduação em Ciências Sociais na então Universidade de Minas Gerais. A reforma funda os dois cursos, formando o atual curso de Graduação (Licenciatura e Bacharelado) em Ciências Sociais, que comporta como áreas de formação os três clássicos campos: Antropologia, Sociologia e Ciência Política.

A primeira notícia que se tem de disciplinas de Antropologia no ensino superior em Belo Horizonte "ocorrem no ano letivo de 1941, nos cursos iniciados na Faculdade de Filosofia” (Souza, 2004, p. 1). A mais antiga referência até agora encontrada relativa à religião em programas de Antropologia refere-se à cadeira de Antropologia e Etnologia ministrada por Orsini de Castro (dermatologista e primeiroprofessor de Antropologia da Faculdade de Filosofia, anos 1950) nos cursos de Geografia e História e no curso de Ciências Sociais. A religião aparece, juntamente com idioma, artes, ciência e escrita, no item relativo à "cultura espiritual", bem como no item "fatores históricos na formação cultural”, ao lado da tradição (Souza, 2004, p. 15).

A Sociologia e a Ciência Política gozaram por um longo período de uma situação de predomínio relativamente à Antropologia. Predomínio que foi consolidado, entre outros fatores, pela criação do Mestrado em Ciência Política (1970), do Mestrado em Sociologia (1980) e do Doutorado em Ciências Humanas: Sociologia e Política (1993).

A subordinaçãohierárquica (para usar a semântica dumontiana)em que se encontrava a Antropologia, não impediu a ativa e produtiva participação

Debates do NER, Porto Alegre, ANo 8, N. 11, P. 119-133, JAN./Jun. 2007 
dos professores de Antropologia e da área como um todo na graduação e na pós-graduação. No mestrado em Sociologia, por exemplo, os antropólogos participaram atravésda oferta regularde disciplinas optativas, da realização de pesquisa e de orientação de dissertações na área de concentração em Sociologia da Cultura(em que a área de Religiãose abrigava), na conduçãode seminários de tese, na participação em bancas examinadoras (quer de dissertações, quer de ingresso de alunos) e mesmo na administração do mestrado.

A situação da antropologia na pós-graduação teve um significativo renversement (Dumont mais uma vez acionado) com a criação em 2005 do Programa de Pós-graduação em Antropologia, que se situa no bojo de toda uma reconfiguração da pós-graduação na área de CiênciasSociais na UFMG. O PPGAN oferece formação em nível de mestrado em duas áreas de concentração, Antropologia Social e Arqueologia, tendo oito linhas de pesquisa, uma delas sendo Antropologia da Religião.

Foi somente com a criação do PPGAN que finalmente pode ser oferecida uma disciplina de Antropologia da Religião num mestrado em Antropologia,o que ocorreu no primeiro semestre de 2007. A aula inaugural dessa disciplina foi ministrada por Pierre Sanchis sob o título Cultura brasileira e religião.

No que tange à graduação, a posição subordinada da Antropologia relativamente à Sociologia e à Ciência Política modificou-se com a reforma curricular ocorrida em 1990, que criou a formação especializada dividida em três áreas de concentração, pondo em paridade numérica a distribuição das disciplinasobrigatórias nas três áreas. Uma importante mudança da reforma diz respeito à introdução da monografia de final de curso, área na qual desde então a atuação da Antropolog ia só tem aumentado quantitativa e qualitativamente.

Fechado o parêntese, retomemos o fio da meada. Pierre participou de vários órgãos colegiados da Universidade, entre os quais, o colegiado do Mestrado em Sociologia, o colegiado do Curso de Filosofia, a câmara do Departamento de Sociologia e Antropologia, o conselho de Pós-Graduação da UFMG. Foi ainda coordenador da extensão da FAFICH. 
Ministrou variadas disciplinas na graduação em Ciências Sociais e no Mestrado em Sociologia, entre as quais: Teoria Antropológica, Antropologia Política, Introdução à Antropologia, Teoria Sociológica e Antropologia da Religião, Seminário de Tese e Seminário de Área de Concentração. Realizou várias pesquisas, entre as quais se destacam: A pastoraloficial da Igreja Católica e o catolicismo popular; As romarias mineiras; As ideologias da Igreja Católica sobreo Brasil:1870-1970; O papa em Belo Horizontee A romariade Congonhas do Campo.

O foco da pesquisa sobre as ideologias da IgrejaCatólica era o das relações entre o exército brasileiroe o clero brasileiroem torno da gerência do modelo "nacional". Relembra ele que nesses tempos (final da década de 1970/início da de 1980) havia uma forte demanda de alunos por cursos optativos sobre Teoria da Religião e, especialm ente, pelas relações entre religião e política na histó ria da socie dade brasi leira, como por exemplo um curso que ele ministr ou sobre Gramsci e os movimentos messiâni cos brasilei ros. Perfeitamente compreensível para o espírito dessa efervescente época que, entre outros, promoveu o tenso e complexo encontro (no mundo acadêmico e na sociedade) entre religiãoe políticae os debatessobre alienação e emancipação, entre outros.

A pesquisa em Congonhas teve a participação de cerca de quarenta alunos e de outros colegas de departamento, entre os quais Ronaldo de Noronha (sociólogo). Sobreela, testemunha: "Ficamos vários dias, dormindona escola, em cima de mesas de classe. Observação participante, por um lado, e questionário no meio dos romeiros. Lembro do entusiasmo!". Incluiuainda trabalho nos arquivos eclesiásticos de Mariana visando à procura de dados sóciohistóricos sobre Congonhas. Entre outros produtos, redundou em uma conferência num simpósio da CEHILA.

A significativa presença de alunos nas atividades de pesquisa de Pierre também se evidencia nos mais de cem alunos que participaram do projeto relativo àv in da do Papa a Belo Horizonte. Recorda-se que os alunos - registrese todos voluntários e oriundos de vários cursos da FAFICH e que haviam sido preparados para a pesquisa por meio de "várias reuniões de estudo" estavam "dispersos desde as primeiras horas da madrugada, ao longo do

Debates do NER, Porto Alegre, ano 8, N. 11, P. 119-133, Jan./Jun. 2007 
trajeto entre o aeroporto e a 'Praça do Papa" ${ }^{5} \mathrm{O}$ trabalho combinou "observaçãoparticipante, múltiplas entrevistas e dois questionários, um antese outro depois da missa e pronunciamentos. Já nas semanas anteriores tinha sido feita uma observação nas igrejas (e locais de culto) tanto católicas quanto evangélicas, para sondar a temática usada pelas instituições para preparar (ou alertar) à população".

Pierre publicou, entre outros, inúmeros artigos em periódicos nacionais e internacionais,capítulos, as versões portuguesa (1983) e francesa (1997) de sua tese de doutorado sobre as romarias portuguesas. Organizou também coletâneas (Sanchis, 2001).

Teve ativa participação em reuniões acadêmicas, como as da Associação de CientistasSociais da Religião do Mercosul, da Sociedade dos Americanistas, da ANPOCS, da ABA, do III Congresso Luso-Afro-Brasileiro de Ciências Sociais, bem como nas conferências da CEHILA. Nesses eventos apresentou quase uma centena de trabalhos.

Foi membro de muitas bancas de mestrado e de doutorado, entre as quais se pode destacar as de Arno Vogel (mestrado) e Luis Felipe Baeta Neves (doutorado). Ele mesmo orientou oito dissertações de mestrado e uma tese de doutorado. Das dissertações, três tratam de temas sobre religião, uma delas, a de Mônica do Nascimento Barros (1995), a primeira dissertação de mestrado no Brasil a tratar da Igreja Universal do Reino de Deus.

Fizeram parte igualmente de suas atividades no departamento, a promoção de seminários e de simpósios. Como o seminário ocorrido por ocasião do lançamento de um número especial da Religião e Sociedade, cujo tema "marxismo e religião" promoveu acalorada discussão entre os presentes.

Foram contemporâneos de Pierre na UFMG e também trabalharam com Antropologia da Religião: Saul Martins, Romeu Sabará, Cleonice Pitangui, Renato Ortiz e Paula Montero. Ana Lúcia Modesto, que também faz parte desse grupo, é a única ainda em atividade.

${ }^{5}$ Praçado Papa, como ficou conhecida a área públicade lazer onde o rezou missa João Paulo II, quando de sua visita ao Brasil em 1980.

Debates do NER, Porto Alegre, ano 8, N. 11, P. 119-133, Jan./Jun. 2007 
Saul Martins atuou sobretudo no campo das culturas negra e popular em Minas Gerais, dedicando-se ao estudo das chamad as manife stações folclóricas, onde freqüentemente encontrava a religião, como é o caso de suas pesquisas sobre a Congada. Personagem complexa e polêmica, manteve correspondênciacom grandesnomes daintelectualidadebrasileira comoEduardo Galvão, Câmara Cascudo e René Ribeiro,entre outros (Souza, 2006, p. 283). $\mathrm{O}$ farto e rico material coletado foi reunido, por ele mesmo, em um museu, que leva seu nome, na cidade de Vespasiano. Seu trabalho foi continuado pelo discípulo Romeu Sabará, que trabalhou com a Congada, especialmente entre os Arturos, e foi o inspirador da Missa Congo, junto com um grupo da PUC-Minas. Cleonice Pitangui trabalhou na área de religiosida de negra popular, tendo pesquisado a Congada e os cultos afro-brasileiros em Minas Gerais.

Foi também na área de cultura popular e religiosidade afro-brasileira que se concentroua atuação de Renato Ortiz no período em que foi professor da UFMG (1977-1984). Neste período, realizou dois pós-doutorados, um em Columbia e outro em New York. Publicou vários artigos, em português e francês, assim como capítulos de livros, com enfoque especial em cultura popular e memória nacional, ideologia e sincretismo religioso. A morte branca do feiticeiro negro (1978) e A consciência fragmentada (1980), dois de seus mais importantes livros, clássicos no campo das religiões afrobrasileiras, datam dessa época.Foi o organizador do númerodedicado a Pierre Bourdieu na prestigiosa coleção Grandes Cientistas Sociais, coordenada por Florestan Fernandes, da qual escreveu a introdução ( $\grave{A}$ procura de uma sociologia da prática; Ortiz, 1983). Teve ativa participação em reuniõesacadêmicas, notadamente na ANPOCS e SBPC, bem como no Congresso dos Americanistas e na Conference of Latin American History.

Paula Montero foi professora da UFMG entre 1978 e 1986. Foi uma das tradutoras da coletânea de textos de Bourdieu organizada por Renato. Em 1983 defende sua tese de doutorado sobre cura mágica na umbanda, na USP, sob a orientação de Eunice Durham, que publicada na forma de livro em 1985 tornou-se uma referência clássica no campo. Em 1985 publica 
outra referência central no campo da Antropologia da Religião, na qual apresenta as principais abordagens da magia no pensamento antropológico.

Ana Lúcia, ela mesma ex-aluna de Pierre, é professora de Antropologia na UFMG desde 1990. Atualmente, desenvolve atividade de ensino e de pesquisa enfocando as relações entre cinema e religião.

Na ocasião da outorga do título de professor emérito da UFMG a Pierre foi realizado o Encontrode CiênciasSociais da Religião - Passagem de milênio e pluralismo religioso na sociedade brasileira: Homenagem a Pierre Sanchis. Esse evento representou o que se poderia chamar de retomada institucional e acadêmica da área da religião na UFMG.

Em 2003 foi lançado um número especial da Revista Teoria\&Sociedade com os textos que foram apresentados no seminário. ${ }^{6}$ É importante observar, sobretudo se se leva em conta a relativamente longa situação de subordinação hierárquicaocupadapelaAntropologia no conjuntodas trêsáreas, queo primeiro de uma sériede números especiais da revista, seja dedicado justamenteà Antropologia da Religião e comoum tributo ao trabalho de Pierre Sanchis. Traz textos de Carlos Alberto Steil, Carlos RodriguesBrandão,João Batista Libânio,Otávio Velho, Patrícia Birman, Paula Montero, Pedro Ribeiro, Regina Novaes, Rita Segato, alguns dos mais importantes intelectuais do campo dos estudos de religião, todos interlocutores de Pierre, outros, mais ainda, companheiros de pesquisa. $\mathrm{O}$ númerotraz aindadois textos de $\mathrm{Pierre}$, um que realiza uma cartografiadas religiões dosbrasileirose outro, um memorial(Sanchis,2003a,2003b).

A partir de 2000, a área da religião na UFMG inicia um período de crescimento simultaneamente quantitativo e qualitativo tanto na área de Sociologia quanto de Antropologia.

Na Sociologia da Religião destaque-se a atuação(no ensinoe na pesquisa) dos professores Alexandre Cardoso e Renan Springer de Freitas. O primeiro trabal ha com Sociologia da Magia, notadamente com as organizações mágico-religiosas e com a magia moderna, tema de sua tese de doutorado

\footnotetext{
${ }^{6}$ Datada de 1997, a revista Teoria\&Sociedade é um empre end imento conju nto do Departamento de Sociologia e Antropologia e do Departamento de Ciência Política.
} 
defendida na USP (1999). O segundo tem se dedicado à Epistemologia e Sociologia da Religião.

Em 2000, foi fundado Centro de Estudos da Religião, batizado Pierre Sanchis. Evidenciand o um outro quadro das relações entre Sociologia e Antropologia, a constituição do CER-Pierre Sanchisfoi um empreendimento conjunto das áreas de Sociologia e Antropologia, representadas respectivamente pelos professores Alexandre Cardoso e Léa Freitas Perez, contando com a participação de um grupo de alunos da graduação em Ciências sociais (André Tavares dos Santos, Cláudio Antônio Cardoso Leite, Flávia Ferreira Pires, Kátia Helena de Jesus, Rita de Fátima Alves Nogueira e Rogério da Silva Paulino) e do mestrado em Sociologia (Luciana de Oliveira).

Até o presente, o CER já desenvolve u quatro pesquisas, duas sobre juventude e religião e duas sobre festas. A primeira delas, que está na origem mesmo de sua constituição - "Religião e Política entre alunos de Ciências Sociais" - foi coordenada nacionalmente pelo professor Carlos Steil, do Núcleo de Estudos da Religião da Universidade Federal do Rio Grande do Sul. O projeto foi realizado em parceria com a Universidade Federal do Rio de Janeiro, a Universidade Federal de Juiz de Fora, a Universidade do Vale dos Sinos e a Pontifícia UniversidadeCatólica do Rio Grande do Sul e teve como inspiração a experiência realizada pela professora Regina Novaes no IFCHSUFRJ nos anos 1990. Na UFMG, a equipe de pesquisadores foi formada pelos já mencionados fundadores do Centro. De cunho quantitativo, usou a técnica de questionário.

A segunda - "Religião, política e cultura entre a juventude de Minas Gerais", financiada pela FAPEMIG - foi realizada em parceria com o Programa de Pós-graduação em Ciência da Religião da UniversidadeFederal de Juiz de Fora e coordenada pelo professor Marcelo Camurça ${ }^{7}$. Usou uma abordagem dupla e articulada de surveye grupo focal.

\footnotetext{
${ }^{7}$ Participaram desta pesquisa, pela UFMG, Léa Freitas Pereze os estudantes de Ciências Sociais Daniela Portella Sampaio, Fernanda Cimini Salles, Marcos Arcanjo de Assis, Pablo Juan Cândido da Silva e Rogério Jerônimo Barbosa.
} 
Os resultadosgerais dessas duas pesquisasencontram-se respectivamente em Debates do NER (Steile Herrera, 2001)e Numen 2004. . Ambas apontam, no que diz respeito aos jovens mineiros, para uma identificação positiva com a religiosidade, embora ser religioso,ter confissão religiosae crer em símbolos religiosos não se localizem necessariamente no mesmo plano e no mesmo nível hierárquico. Em decorrência, o interessepela religiãosuplanta em muito o interesse pela política.

A terceira, "Festa e civilização nos trópicos" visava ampliar o campo de reflexão sobre a organização da sociedade brasileira através de uma análise da festa,tomada como um dos modos de expressão privilegiado da complexidade de formas do vínculo social. ${ }^{9}$ Os resultados mais gerais desta pesquisa foram publicados sob a forma artigos (Perez, 2000, 2002, 2003, 2005).

A quarta, ainda em andamento, é um desdobramento particularizado da terceira, intitulando-se "Cartografia das festas em Minas Gerais - por seus viajantes e cronistas" ${ }^{10}$. Financiada pela FAPEMIG e pelo $\mathrm{CNPq}$, segue uma pergunta central, de cunho conceitual, a saber: o que é a festa, qual é o seu lugar na vida coletiva, sobretudo num país como o Brasil (que afinal é o país do carnaval e disso muito se ufana), tomando como objeto de estudo as festas religiosas (expressões mais tradicionais e características do fenômeno

\footnotetext{
${ }^{8}$ Essas pesquisas foram amplamente discutidas em eventos acadêmicos como a IV Reunião de Antropologia do Mercosul (200 1, simpósio n. 5 - Juventude, Ciências Sociais e Religião, coordenado por Carlos AlbertoSteile Léa Freitas Perez), na 24a Reunião Brasileira de Antropologia (2004, Fórum de Pesquisa Juventudes: cultura e espaço urbano; religião e política, coordenado por Rosilene Alvim e Léa Freitas Perez), nas XIII Jornadas sobre Alternativas Religiosas na América Latina (2005, no grupo de trabalhoJuventude e religião: modulações e articulações com a cultura, socialidade e política, coordenados por CarlaCoelho de Andrade e Léa Freitas Perez).

${ }^{9}$ Participaram dessapesquisaLéa FreitasPereze os estudantes de Ciências Sociais Amélia Corrêa Passos, Kátia Helena de Jesus e Rosana Alexandre dos Santos, que forambolsistas de iniciação científica do CNPq e FAPEMIG.

${ }^{10}$ Participam dessa pesquisa Léa Freitas Perez e os estudantes de ciências sociais AndréTavares Silva Santos, Diogo Neves Pereira, Leila Schoenenkorb da Silva, Marcos da Costa Martins, Rafael Barros Gomes. Alguns deles foram ou são bolsistas de iniciação científica do CNPq e FAPEMIG e do Programa de Tutoramento da UFMG.
} 
festivo) em Minas Gerais (espaço privilegiado do florescimento da festa barroca, uma das mais influentesmatrizes da cultura da brasileira)no período compreendido entre o século XVII e o século XIX, tal como vistas, descritas e analisadas por viajantes e cronistas que estiveram na região, sobretudo na zona mineradora.

Estas pesquisas e seus desdobramentos têm sido discutidos em vários eventos acadêmicos e têm gerado um bom número de monografias de graduação em ciências sociais e dissertações de mestrado ${ }^{11}$.

Umsegmentodas atividades do CERé a promoçãode eventosacadêmicos, notadamente seu ciclo anual de palestras, do qual já participaram como convidados: Antônio Flávio Pierrucci, Cecília Mariz, Emerson Giumbelli, Fátima Tavares, Marcelo Camurça, Maria das Dores Campos Machado, Otávio Velho, Pablo Séman, Reginaldo Prandi Palestrante, Regina Novaes, Vagner Gonçalves da Silva e Vitória Peres (de saudosa memória).

Desde a fundação do centro, já foram defendidas dezoito monografias de graduação (das quais doze de antropologia da religião e seis de sociologia da religião) e sete dissertações de mestrado em sociologia (quatro em sociologia da religião e três em antropologia) ${ }^{12}$. Esses trabalhos tratam de temas variados da atualidade religiosa brasileira e mineira, desde as manifestações religiosas festivas (congado, catopês) passando pela Nova Era, movimento carismático, islamismo, umbanda, conversão, magia, etc. Encontra-se em elaboração uma tese de doutorado, a primeira em sociologia da religião, que trata da problemática da conversão ao islamismo no Brasil e em Portugal.

\footnotetext{
${ }^{11}$ Entre outros eventos: na 24a Reunião Brasileira de Antropologia (2004, no simpósio “Festa em perspectiva e como perspectiva”, coordenado por Léa Freitas Perez); no Colóquio Festase sociabilidades (2006, conferência de abertura e comunicação de pesquisa); na 25a Reunião Brasileira de Antropologia (2006, Grupo de Trabalho "Festa e cultura", coordenado por Léa Freitas Perez e Roberto Motta). Já foram produzidas oito monografias de bacharelado em Ciências Sociais e duas dissertações de mestrado em Sociologia.

12 Esse número é bastante significativo se se levar em conta a história recente do Centro. $\mathrm{O}$ mestrado em Antropologia, rebento novo, ainda não tem nenhuma dissertação defendida. Das em andamento, três são na área de Antropologia da Religião, duas das quais tratam da temática da festa religiosa.
}

Debates do NER, Porto Alegre, ano 8, N. 11,P. 119-133, JAN./Jun. 2007 
Ao fim e ao cabo voltamos - como sempre - ao começo. O ensino e a pesquisa na área da Religião na UFMG, notadamente em Antropologia da Religião, começam de modo sistemático e se consolidam com Pierre Sanchis. O que é feito hoje é, em grande medida, uma continuida de nas atenções destacadas, mesmo que em densidades diferentes. Para falar como ele, tratam-se dos mesmos níveis diferentemente articulados: temas e questões candentes da atualidade religiosa mundial, traços culturais e sociológicos que caracterizam as religiões dos brasileiros e suas variantes mineiras.

Do que se disse aqui sobre a área de Religião na UFMG, de sua relação fundamental com o trabalho de Pierre Sanchis e do que hoje se produz, poder-se-ia fazer ecoar a afirmação maussiana sobre a religião em geral e sua concretudeparticular: "umareligião determinadanão é senão uma espécie de abstração, de extrato convencional da vida religiosa de todos os seus adeptos. Ora, esta vida religiosa não se expandiu de uma forma uniforme entre todos os indivíduos. Cada um a refrata de seu modo e subgrupos numerosos se formam em toda religião, mais ou menos estáveis, mais ou menos isolados, onde a religiãodada é percebidade um certo ponto de vista e praticadade um certo modo" (Mauss, 1968, p. 99). O sagrado e suas admiráveis e infinitas metamorfoses...

\section{REFERENNCIAS}

BARROS, Mônica do Nascimento. A batalha do Armagedon: uma análise do repertório mágico-religioso proposto pela Igreja Universal do Reino de Deus. Dissertação (Mestrado em Sociologia)-PPGS/FAFICH/UFMG, Belo Horizonte, 1995.

BOURDIEU, Pierre. PierreBourdieu:Sociologia.In: ORTIZ,Renato, (Org.). São Paulo: Ática, 1983, n. 39. (Coleção Grandes Cientistas Sociais, tradução de Paula Montero e Alícia Auzmendij).

CARDOSO, Alexandre. Os alquimistas já chegaram: uma interpretação sociológica das práticas mágicas. Tese (Doutorado em Sociologia) - Programa de Pós-Graduação em Sociologia/USP, São Paulo, 1999. 
MAUSS, Marcel. Généralités sur la théorie des religions. Oeuvresv. 1: Les fonctions sociales du sacré. Paris: Les Editions de Minuit, 1968.

MONTERO, Paula. Da doença à desordem: a magia na umbanda. Rio de Janeiro: Graal, 1985.

___ Magia e pensamento mágico. São Paulo: Ática, 1986.

NUMEN, v. 7, n. 1. Juiz de Fora: Editora da UFJF, 2004.

ORTIZ, Renato. A morte branca do feiticeiro negro. Petrópolis: Vozes, 1978.

A consciência fragmentada: ensaios de cultura popular e religião.

Rio de Janeiro: Paz e Terra, 1980.

PEREZ, Léa Freitas. O ensino de Antropologia em Belo Horizonte. In: ECKERT, Cornélia; GODÓI, Emília Pietrafesa de (Org.). Homenagens: Associação Brasileira de Antropologia - 50 anos. Florianópolis: Nova Letra, 2006.

—__ . "Le métissage au Brésil vu à travers les fêtes". 2003. Hermès, n. 35. Paris, CNRS Editions.

. Dionísio nos trópicos: festa religiosa e barroquização do mundo por uma antropologiadas efervescências coletivas. In: PASSOS, Mauro(Org.). A festa na vida: significado e imagens. Petrópolis: Vozes, 2002.

. Breves notas sobre a religiosidade brasileira. Brasil 500 anos. Edição Especial. Belo Horizonte: ImprensaOficial dos Poderes do Estado,jun. 2000.

PEREZ, Léa Freitas; SANTOS, André Tavares Silva. Pierre Sanchis e o exercício escrupuloso do ofício: em busca de suas nascentes, as romarias portuguesas. Ciencias Sociales y Religíon/Ciências Sociaise Religiãon. 7, ano 7, 2005.

SANCHIS, Pierre. A graça e a gratidão. Teoria\&Sociedade. Belo Horizonte: UFMG, 2003a.

——_. A religião dos brasileiros. Teoria\&Sociedade. Belo Horizonte: UFMG, 2003b.

(Org.). Fiéis \& cidadãos: percursos de sincretismo no Brasil. Rio de Janeiro: EdUERJ, 2001. 
SANCHIS, Pierre. Arraial: la fête d'un peuple - les pèlerinages populaires au Portugal. Paris: École des Hautes Études en Sciences Sociales, 1997. 1992a.

____ (Org.). Catolicismo: modernidade e tradição. São Paulo: Loyola, 1992b.

____ (Org.). Catolicisma unidade religiosa e pluralismocultural. São Paulo: Loyola, 1992c.

Arraial: festa de um povo. As romarias portuguesas. Lisboa: Publicações Dom Quixote, 1983.

SOUZA, Candice Vidal e. A construção da posição institucional da Antropologia em Minas Gerais: estudo sobre hierarquias intelectuais e lutas de classificação nas ciências sociais. In: XXIVREUNIÃO DA ASSOCIAÇÃO BRASILEIRA DE ANTROPOLOGIA. Olinda, 2004.

STEIL, Carlos Alberto; HERRERA, Sonia Reyes (orgs.). Debates do NER 2: Religião, política e ciências sociais. Porto Alegre: NER/PPGAS/UFRGS, 2001. 



\section{INSTRUÇÕES PARA OS AUTORES}

1 Debates do NER publicará trabalhos inéditos sob a forma de artigos em português.

2 Os artigos devem ser escritos em espaço 1,5 e ter até 10 mil palavras, incluindo referências e notas.

3 Os artigos devem vir acompanhados de um resumo escrito em espaço simples, com até 150 palavras e mais quatro palavras-chave, além de uma versão em inglês do resumo (Abstract), nos mesmos padrões, com quatro palavras-chave (Keywords).

4 Nos artigos e resenhas, as notas explicativas devem vir no rodapé da página e as referências devem vir após o texto, ordenadas alfabeticamente.

5 No corpo do texto, a indicação de referência nas citações diretas deve trazer autor(es), ano de publicação e página(s); nas citações indiretas, a indicação de página é opcional, conforme os modelos:

Segundo Hassen (2002, p. 173): "Há uma grande carência de materiais didáticos nesse campo, principalmente se aliados à ludicidade."

Sabemos da grandecarência de materiais didáticos nesse campo,segundo Hassen (2002, p. 173).

6 As citações diretas com mais de três linhas, no texto, devem ser destacadas com recuo e corpo menor de letra, sem aspas, em espaço simples; transcrições das falas dos informantes seguem a mesma norma, conforme o modelo:

[...] regras de comportamentoexplícitos às quaisos indivíduosse referem conscientemente,e que se fundam sobre justificações ou princípios filosóficos, ideológicos ou políticos, ou sobreo surgimentode novasaspiraçõesindividuais ou coletivas. (Bozon, 1995, p. 124). 
7 As referências, no final do texto, devem seguir os modelos:

7.1 Livro (e guias, catálogos, dicionários, etc.) no todo: autor(es), título (em itálico e separado por dois-pontos do subtítulo, se houver), número da edição (se indicado), local, editora, ano de publicação:

DUMONT, Louis. Homo hierarchichus: o sistema de castas e suas implicações. São Paulo: EDUSP, 1992.

FORTES, Meyer; EVANS-PRITCHARD, E. E. (Org.). African political systems. Oxford: Oxford University Press, 1966.

MINISTÉRIO DE SALUD. Unidade Coordinadora Ejecutora VIH/SIDA y ETS. Boletín de SIDA: programa nacional de lucha contra los retrovirus del humano y SIDA. Buenos Aires, mayo 2001.

7.2 Parte de livro (fragmento, artigo, capítulo em coletânea): autor(es), título da parte seguido da expressão "In:", autor(es) do livro, título (em itálico e separado por dois-pontos do subtítulo, se houver), número da edição (se indicado), local,editora, ano de publicação, página(s) da partereferenciada:

VELHO, Otávio.Globalização: antropologiae religião. In: ORO, Ari Pedro; STEIL, Carlos Alberto. Globali zação e religião. Petrópolis: Vozes, 1997. p. 25-42.

7.3 Artigo/matéria em periódico (revista, boletim, etc.): autor(es), título do artigo, nome do periódico (em itálico), local, ano e/ou volume, número, páginas inicial e final do artigo, data.

CORREA, Mariza. O espartilho de minha avó: linhagens femininas na antropologia. Horizontes Antropológicos, Porto Alegre, ano 3, n. 7, p. 70-96, out. 1997. 
7.4 Artigo/matéria em jornal: autor(es), título do artigo, nome do jornal (em itálico), local, data, seção ou caderno, página (se não houver seção específica, a paginação precede a data):

TOURAINE, Alain. O recuo do islamismo político. Folha de São Paulo, São Paulo, 23 set. 2001. Mais!, p. 13.

SOB as bombas. Folha de São Paulo, São Paulo, p. 2, 22 mar. 2003.

7.5 Trabalhos acadêmicos: referência completa seguida do tipo de documento, grau, vinculação acadêmica, local e data da defesa conforme folha de aprovação (se houver):

GIACOMAZZI, M. C. G. O cotidiano da Vila Jardim: um estudo de trajetórias, narrativas biográficas e sociabilidade sob o prisma do medo na cidade. 1997. Tese (Doutorado em Antropologia Social)-PPGAS/UFRGS, Porto Alegre, 1997.

7.6 Evento no todo: nome do evento, numeração (se houver), ano e local (cidade) de realização, título do documento (anais, atas, resumos, etc., em itálico), local de publicação, editora e data de publicação:

REUNIÃO DA ASSOCIAÇÃO BRASILEIRA DE ANTROPOLOGIA, 21., 1998, Vitória. Resumos... Vitória: Departamento de Ciências Sociais/ UFES, 1998.

7.7 Trabalho apresentado em evento: autor(es), título do trabalho apresentado seguido da expressão "In:", nome do evento, numeração (se houver), ano e local (cidade) de realização, título do documento (anais, atas, resumos, etc., em itálico), local de publicação, editora, data de publicação e página inicial e final da parte referenciada:

STOCKLE, Verena. Brasil: uma nação através das imagens da raça. In: REUNIÃO DA ASSOCIAÇÃO BRASILEIRA DE ANTROPOLOGIA, 21., 1998, Vitória. Resumos... Vitória: Departamento de Ciências Sociais/ UFES, 1998. p. 33. 
8 Nos textos, evitar o uso de mais de uma fonte; usar inicial maiúscula somente quando imprescindível; os recursos tipográficos devem ser utilizados uniformemente:

a) itálico:para palavrasestrangeiras, títulos(livros, eventos,etc.) e ênfase;

b) aspas duplas: citações diretas com menos de três linhas, citações de palavras individuais ou palavras cuja conotação ou uso mereça destaque;

c) negrito e sublinhado: devem ser evitados.

9 Os autores de artigos e resenhas devem ser identificados, apresentando suas filiações institucionais e endereços completos para contato e e-mail.

10 Os artigos devem ser enviados em 3 cópias impressas e em disquete, em arquivo no formato Rich Text (.rtf) ou Word (.doc), compatível com plataforma Windows.

11 A publicação dos artigos será condicionadaà aprovação da Comissão Editorial Executiva, considerando pareceres de consultores externos.

12 Os autores de artigos ou resenhas receberão 2 exemplares da revista na qual seus trabalhos forem publicados. 
Impressão e editoração: 